\title{
QUALIDADE TECNOLÓGICA DA CANA-DE-AÇÚCAR EM FUNÇÃO DA APLICAÇÃO DE MATURADORES EM MEIO DE SAFRA $\left({ }^{1}\right)$
}

\author{
GLAUBER HENRIQUE PEREIRA LEITE $\left({ }^{2}\right)$; CARLOS ALEXANDRE COSTA CRUSCIOL $\left({ }^{2, *}\right)$; \\ MARCELO DE ALMEIDA SILVA $\left({ }^{3}\right)$; WALDEMAR GASTONI VENTURINI FILHO $\left({ }^{4}\right)$
}

\begin{abstract}
RESUMO
O fornecimento de matéria-prima de qualidade tecnológica é fundamental para garantir o rendimento industrial. O objetivo deste trabalho foi avaliar a qualidade tecnológica da cana-de-açúcar em função da aplicação de maturadores da classe dos inibidores do crescimento (Glifosato, Sulfometuron metil e Compostos de radicais carboxílicos orgânicos + Glifosato) em meio de safra. O experimento foi desenvolvido em cana-soca por duas safras consecutivas (2004/2005) na Fazenda Bosque, Igaraçu do Tietê (SP), sendo os tratamentos aplicados em 10/5/2004 e 4/8/2005. Os tratamentos foram constituídos da aplicação de três reguladores vegetais da classe dos inibidores do crescimento (Sulfometuron metil, Glifosato e Compostos de radicais carboxílicos orgânicos + Glifosato) e uma testemunha (maturação natural). A eficiência agronômica dos maturadores foi influenciada pela condição climática de cada safra. A aplicação dos maturadores em meia estação (maio) permitiu explorar de forma significativa o potencial genético da variedade quanto ao acúmulo de sacarose nos colmos, implicando em melhoria na qualidade tecnológica da matéria-prima, porém sem efeito significativo na produtividade de colmos por hectare. Os maturadores influenciaram de forma significativa a produtividade de açúcar, aumentando o retorno econômico por hectare.
\end{abstract}

Palavras-chave: Saccharum spp., maturadores, glifosato, sulfometuron metil, maturação.

\section{ABSTRACT \\ TECHNOLOGICAL QUALITY OF SUGARCANE UPPON APPLICATION OF RIPENERS DURING THE CROPPING SEASON}

The supply of raw material with high technological quality is the most important issue to guarantee industrial productivity. The objective of this work was to evaluate the technological quality sugarcane uppon application of ripeners from the class of growth inhibitors (Sulfomethuron methyl, Glyphosate and Compounds of organic carboxylic radicals + Glyphosate) in the middle of the cropping season. The experiment was carried out in ratoon cane during two subsequent crops (2004/2005) at Bosque Farm, Igaracu do Tietê (SP), and treatments application in May 10, 2004 and August 04, 2005. The treatments consisted of three plant regulators application and a control (natural ripening). Agronomic efficiency was influenced by weather conditions in each crop season. The ripeners application in May 10, 2004 increased the sucrose content in stems, resulting in improvement of technological quality of raw material, but not affecting the productivity of stems. The ripeners influenced significantly the sugar production of witch increase the overall economic revenue.

Key words: Saccharum spp., ripeners, glyphosate, sulfomethuron methyl, ripening.

( $\left.{ }^{1}\right)$ Extraído da dissertação de mestrado apresentado pelo primeiro autor à Faculdade de Ciência Agronômicas (FCA), Universidade Estadual Paulista (UNESP). Campus de Botucatu. Recebido para publicação em 19 de dezembro de 2007 e aceito em 29 de novembro de 2008

$\left(^{2}\right)$ Universidade Estadual Paulista, Faculdade de Ciências Agronômicas, Departamento de Produção Vegetal, Caixa Postal 237, 18610-307 Botucatu (SP). E-mail: ghpleite@fca.unesp.br; E-mail: crusciol@fca.unesp.br (*) Autor correspondente.

$\left({ }^{3}\right)$ Agência Paulista de Tecnologia dos Agronegócios (APTA) - APTA Regional Centro Oeste-Jaú, Caixa Postal 66, $17201-970$ Jaú (SP). E-mail: marcelosilva@apta.sp.gov.br

$\left({ }^{4}\right)$ Universidade Estadual Paulista (Unesp), Faculdade de Ciências Agronômicas, Departamento de Gestão e Tecnologia Agroindustrial, 18603-970 Botucatu, SP. E-mail: venturini@fca.unesp.br 


\section{INTRODUÇÃO}

A maturação da cana-de-açúcar refere-se a um dos aspectos fundamentais para o sistema de produção da indústria sucroalcooleira, uma vez que o fornecimento contínuo de matéria-prima de elevada qualidade interfere no seu rendimento industrial (Deuber, 1988). O processo de maturação da cana-deaçúcar na Região Sudeste do Brasil ocorre naturalmente a partir do mês de abril/maio. Neste período, as condições climáticas, determinantes para tal processo, caracterizam-se pela gradativa queda da temperatura e diminuição das precipitações pluviais. Durante o período que compreende a safra agrícola da cana-de-açúcar, tais condições têm influência direta sobre a ocorrência do processo de maturação natural, podendo estimular o desenvolvimento vegetativo da planta em contrapartida ao acúmulo de sacarose, comprometendo a qualidade e o fornecimento de matéria-prima à indústria sucroalcooleira (DEUBER, 1988).

Neste contexto, o emprego de maturadores tem sido de significativa relevância para o suprimento do complexo industrial, tendo em vista que permite induzir o processo de maturação da cana-de-açúcar mesmo sob condições climáticas que favorecem a vegetação e, por consequência, dispor às unidades industriais matéria-prima de qualidade (CAstro, 2000a,b). Atualmente, na busca pela ampliação do período de moagem aliado ao provimento de matéria-prima de elevada qualidade tecnológica à indústria, a utilização de maturadores tem se tornado imprescindível no alcance deste objetivo.

Maturadores, definidos como reguladores vegetais, são compostos químicos capazes de modificar a morfologia e a fisiologia da planta, podendo ocasionar modificações qualitativas e quantitativas na produção.

Esses compostos possibilitam, dentre outros benefícios, retardar ou inibir o desenvolvimento vegetativo, incrementar o teor de sacarose, tornar a maturação precoce, aumentar a produtividade de colmos e açúcar, permitindo explorar o máximo potencial genético das variedades quanto ao acúmulo de sacarose (CASTRO, 1999; LAVANHOLI et al., 2002; Almeida et al., 2003; Caputo et al., 2008).

O objetivo deste trabalho foi avaliar a qualidade tecnológica da cana-de-açúcar em função da aplicação de maturadores da classe dos inibidores do crescimento (Glifosato, Sulfometuron metil e Compostos de radicais carboxílicos orgânicos + Glifosato) em meio de safra.

\section{MATERIAL E MÉTODOS}

O experimento foi desenvolvido em cana-soca (1..$^{\circ}$ corte realizado em $\left.21 / 10 / 2003\right)$ por dois anos consecutivos (2004 e 2005) na Fazenda Bosque, no município de Igaraçu do Tietê, Estado de São Paulo (latitude de $22^{\circ} 38^{\prime \prime} 45^{\prime \prime} \mathrm{S}$, longitude $48^{\circ} 36^{\prime} 29^{\prime \prime} \mathrm{W}$ e altitude de $620 \mathrm{~m}$ ). O clima predominante da região é o Aw (Köppen), com clima seco definido, temperatura média anual de $21,6{ }^{\circ} \mathrm{C}$, umidade relativa média anual de $70 \%$, com extremos de $77 \%$ em fevereiro e $59 \%$ em agosto, sendo a precipitação pluvial média de 1344 $\mathrm{mm}$. Os dados climáticos mensais, referentes à precipitação pluvial e às temperaturas máxima, média e mínima, registradas durante o período de manejo do experimento foram coletados na Estação Meteorológica da Fazenda São Joaquim (Figura 1).

O delineamento experimental foi em blocos casualizados, com cinco repetições. Os tratamentos constituíram-se da aplicação de três reguladores vegetais da classe dos inibidores de crescimento (Sulfometuron metil, Glifosato e Compostos de radicais carboxílicos orgânicos (C.C.) + Glifosato) e uma testemunha (maturação natural). Os produtos comerciais empregados foram Curavial (750 g i.a. $\mathrm{kg}^{-}$ $\left.{ }^{1}\right)$, Roundup (480 g i.a. $\left.L^{-1}\right)$ e MTD (pool de aminoácidos com marcador em L-alpha-metionina) + Roundup (480 g i.a. $\mathrm{L}^{-1}$ ), adotando-se a dosagem recomendada pelos fabricantes, ou seja, $20 \mathrm{~g} \mathrm{ha}^{-1}, 0,4$ $\mathrm{L} \mathrm{ha}^{-1}$ e $1 \mathrm{~L} \mathrm{ha}^{-1}+0,15 \mathrm{~L} \mathrm{ha}^{-1}$ respectivamente, sem a adição de adjuvantes. Cada parcela foi constituída por 8 linhas de $10 \mathrm{~m}$ de comprimento, espaçadas de 1,5 $\mathrm{m}$. Para as avaliações, as 6 linhas centrais foram consideradas, desprezando $1 \mathrm{~m}$ nas extremidades e perfazendo uma área útil de $72 \mathrm{~m}^{2}$.

Utilizou-se a variedade SP80-3280, reconhecida por ter elevado teor de sacarose e produtividade em soqueira, maturação média para tardia, boa brotação de soqueiras, floração, no entanto acompanhado por pouco chochamento, além de perfilhamento intermediário (COOPERATIVA DE PRODUTORES DE CANA, AÇúCAR E ÁlCOOL DO ESTADO DE SÃo PAULO, 1997).

A aplicação dos maturadores foi realizada em $10 / 5 / 2004$ e 4/8/2005 por meio de equipamento costal pressurizado $\left(\mathrm{CO}_{2}\right)$ com barra de $6 \mathrm{~m}$ de comprimento, em forma de $\mathrm{T}$, contendo seis pontas de pulverização AXI 11002, sendo a pressão de trabalho de 50 psi para a vazão de $100 \mathrm{~L} \mathrm{ha}^{-1}$. As aplicações realizadas em meses diferentes, na primeira e segunda safras, tiveram por objetivo verificar a eficiência da aplicação dos maturadores em meio de safra. Para tanto, mediante informações de previsões de chuvas concedidas pelo IPMET/UNESP, referentes à probabilidade de ocorrência de precipitações pluviais no período de colheita, realizou-se a implantação do experimento. 

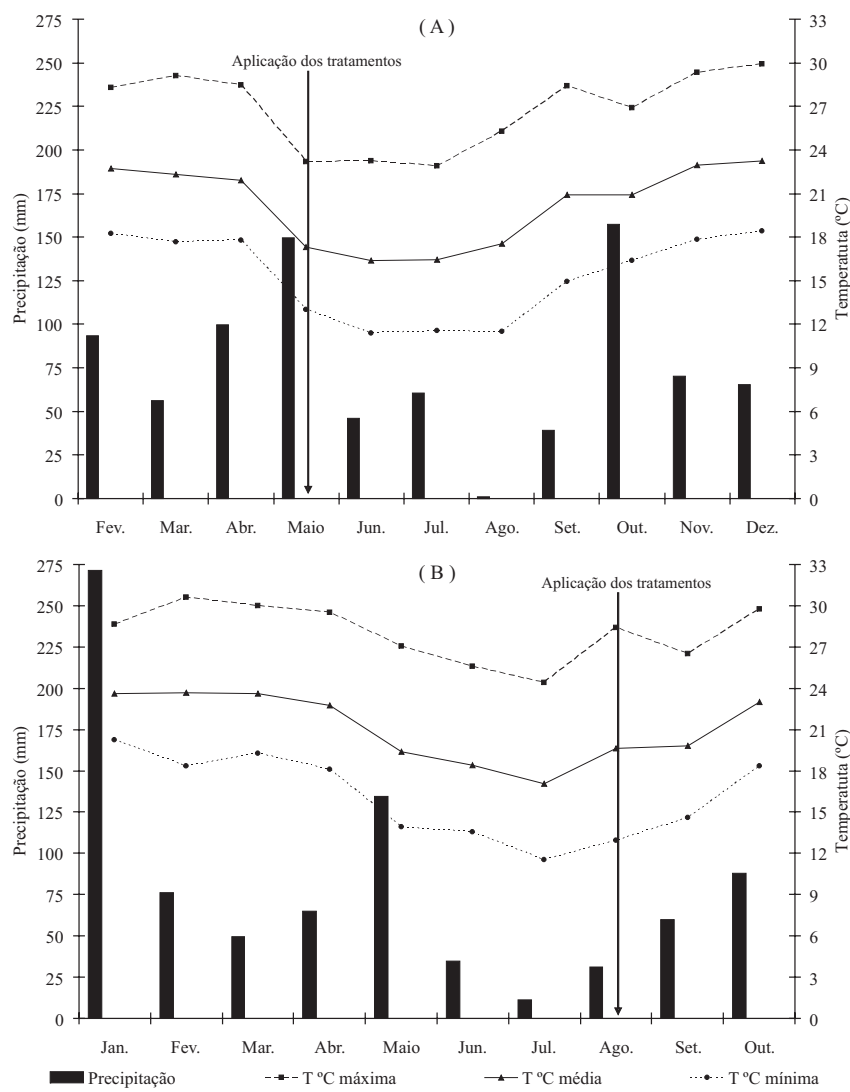

Figura 1. Variação mensal de precipitação pluvial e temperatura do ar (máxima, média e mínima) durante o período de manejo do experimento nas safras 2004 (A) e 2005 (B) em Igaraçu do Tietê (SP).

As produtividades de colmos (TCH) e açúcar (TAH), por ocasião da colheita, foram determinadas nas quatro fileiras centrais e duas fileiras de plantas foram destinadas às mensurações tecnológicas, realizadas nas seguintes épocas: $0,15,30,45,60$, 75, 90 e 174 dias após aplicação (DAA) em 2004 e aos 0 , 15, 30, 60 e 90 DAA em 2005. Uma vez quantificado os parâmetros TCH e TAH, foi estabelecida a margem de contribuição agrícola (MCA), segundo FERNANDES (2003). Nas duas fileiras de plantas foi considerado de forma aleatória $1 \mathrm{~m}$ linear de plantas em cada época de amostragem, sendo os colmos coletados, submetidos ao desponte na altura da gema apical, à desfolha e encaminhados para o Laboratório de Bebidas, Departamento de Gestão e Tecnologia Agroindustrial, Faculdade de Ciências Agronômicas (FCA/UNESP), campus de Botucatu. Esse material foi processado, segundo o método do Sistema de Pagamento de Cana pelo Teor de Sacarose (SPCTS), conforme descrito em Fernandes (2003), sendo considerados os parâmetros pol da cana (PCC), pureza do caldo (PUR), açúcares redutores na cana (ARC) e fibra na cana (F).
Os resultados foram submetidos à análise de variância e as médias dos tratamentos comparadas pelo teste de Duncan a 5\% de probabilidade. Os resultados das épocas de amostragem foram submetidos à análise de regressão, adotando-se como critério para escolha do modelo a significância a $1 \%$ e $5 \%$ de probabilidade (pelo teste F) dos coeficientes de regressão.

\section{RESULTADOS E DISCUSSÃO}

$\mathrm{Na}$ safra 2004, os regimes hídrico e térmico favoreceram o desenvolvimento vegetativo da canade-açúcar, tendo em vista a disponibilidade hídrica de março a julho e o declínio da temperatura de maio a agosto (Figura 1A). Por outro lado, na safra 2005, o processo de maturação natural foi favorecido pela menor precipitação pluvial no intervalo de maio a julho, com pequenas diferenças em relação à safra anterior quanto ao regime térmico (Figura 1B).

O teor de sacarose nos colmos foi aumentado com o transcorrer das épocas de amostragem na safra 2004 (Figura 2A). Nessa safra, os efeitos dos tratamentos ajustaram-se a modelos quadráticos, sendo determinado o máximo acúmulo de sacarose aos 137 e 142 DAA para os tratamentos testemunha e C.C. + Glifosato (PCC = $15,12 \%$ e $15,34 \%$ respectivamente) e aos 136 e 138 DAA para os tratamentos Glifosato ( $\mathrm{PCC}=16,15 \%)$ e Sulfometuron metil $(15,98 \%)$ respectivamente (Figura 2A). Na safra 2005, apenas os tratamentos controle e Sulfometuron metil foram ajustados à função quadrática (Figura 2E). Contudo, o tratamento Sulfometuron metil induziu decréscimo nos valores de pol cana até os 17 DAA, cujo teor calculado foi de $13,94 \%$, com posterior incremento persistente até a colheita; para o controle, o máximo acúmulo de sacarose ocorreu aos 78 DAA, cujo teor calculado foi de 14,79\% (Figura 2E).

Pelos resultados de pesquisa, verifica-se incremento significativo do conteúdo de sacarose em todas as seções do colmo da cana-de-açúcar com o uso de Glifosato (Romero et al., 1996; Romero et al., 1998; ROMERO et al., 2000; ROMERO et al., 2003), corroborando com CASTRO et al. (2002), os quais relataram aumento significativo de PCC aos 20 e 41 DAA na variedade SP70-1143 em relação ao controle, em função da aplicação precoce deste agente químico.

Da mesma forma, diversos autores mencionaram resposta significativa e positiva em relação ao acúmulo de sacarose, decorrente da aplicação de Sulfometuron metil em diferentes épocas e em distintas variedades de cana-de-açúcar, mesmo sob condições climáticas favoráveis ao desenvolvimento vegetativo da planta (CASTRO et al., 1994; Castro et al., 2003; Fernandes et al., 2002; Almeida et al., 2003; CAPUTO et al., 2008). 

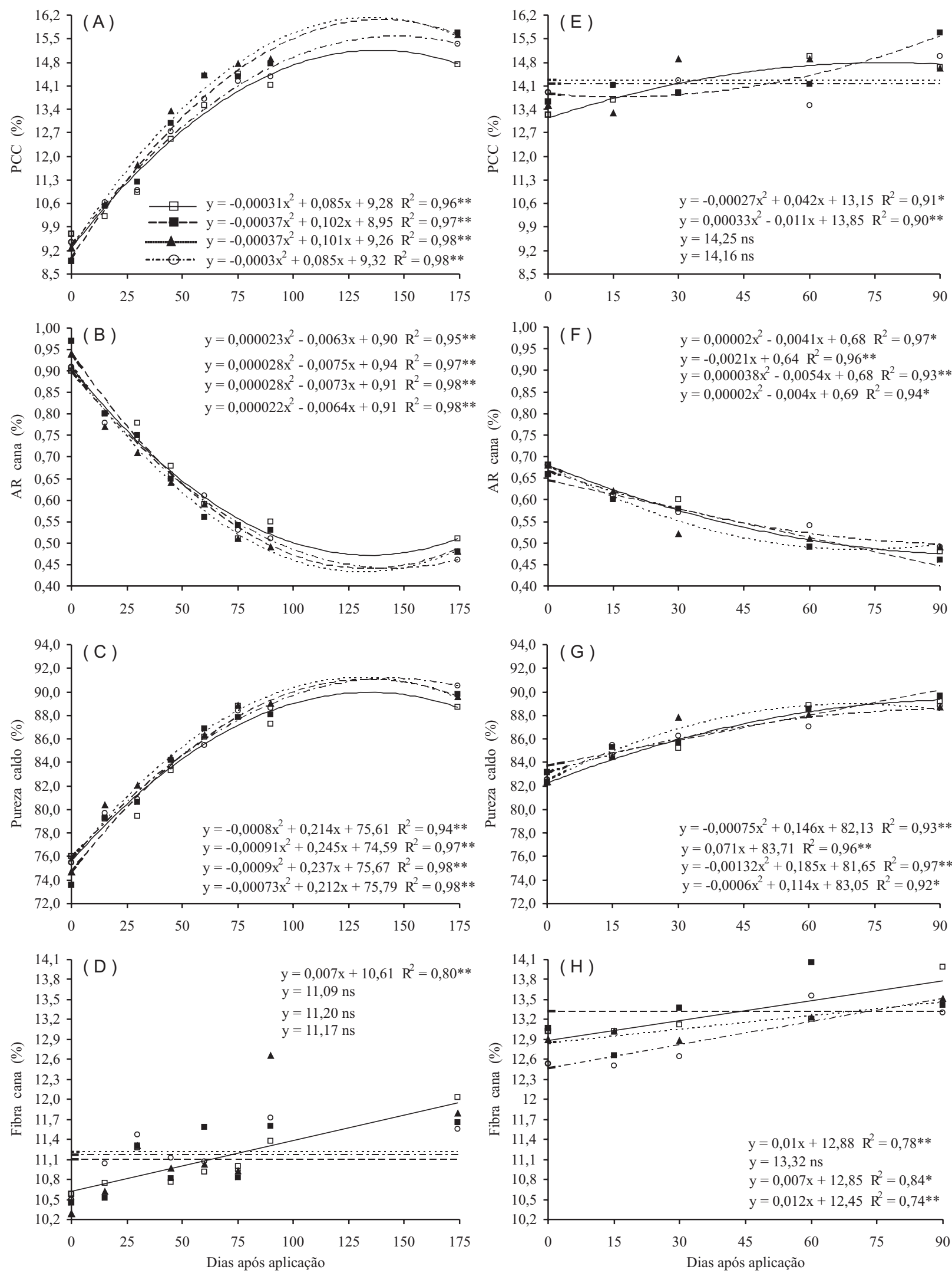

Figura 2. PCC da cana (\%), AR na cana (\%), Pureza do caldo (\%) e Fibra na cana (\%) em função da aplicação dos tratamentos testemunha $(\square)$, Sulfometuron metil $(\mathbf{\square})$, Glifosato $(\boldsymbol{\Delta})$ e C.C. + Glifosato $(\mathrm{O})$ na variedade de canade-açúcar SP80-3280, Igaraçu do Tietê, SP, na safra 2004 (A, B, C, D) e na safra 2005 (E, F, G, H). ns: Não significativo. $* \mathrm{e}^{* *}$ : Significativo pelo teste $\mathrm{F}$, respectivamente, a $5 \%$ e $1 \%$ de probabilidade. 
Independentemente do tratamento, o teor de ARC decresceu com o decorrer das amostragens nas safras 2004 e 2005 (Figuras 2B, F). Os tratamentos propiciaram resposta expressa por modelo quadrático negativo na safra 2004 (Figuras 2B), enquanto em 2005, o tratamento Sulfometuron metil foi ajustado ao modelo linear e os demais tratamentos revelaram padrão de comportamento semelhante à safra anterior (Figura 2F). Em 2004, os tratamentos Sulfometuron metil e Glifosato propiciaram menor teor de ARC aos 134 e 130 DAA, cujos valores foram $0,44 \%$ e $0,43 \%$, respectivamente, enquanto na testemunha e no tratamento C.C. + Glifosato este comportamento ocorreu aos 137 e 145 DAA (ARC $=0,47 \%$ e $0,43 \%$, respectivamente) (Figura 2B). Em 2005 o teor mínimo calculado de ARC ocorreu aos 75 DAA para o tratamento Glifosato (ARC $=0,49 \%$ ) (Figura 2F), enquanto para o tratamento Sulfometuron metil este teor foi de $0,45 \%$ aos 90 DAA.

Os resultados estão de acordo com outros trabalhos de pesquisas, os quais têm revelado redução significativa nos níveis de ARC em caldo de diversas variedades de cana-de-açúcar pela aplicação de Sulfometuron metil e Glifosato (ROMERO et al., 2000; CASTRO et al., 2002; Fernandes et al., 2002; CAPUTO et al., 2008).

Os tratamentos elevaram, de forma significativa, a pureza do caldo da cana-de-açúcar, com resposta expressa por modelo quadrático positivo nas safras 2004 e 2005 (Figuras 2C, G). Todavia o tratamento Sulfometuron metil revelou ajuste linear em 2005 e o C.C. + Glifosato, menor pureza que a testemunha a partir dos 30 DAA (Figura 2G). Em 2004, a máxima pureza do caldo foi atingida aos 126, 134, 135 e 145 DAA para os tratamentos Glifosato (PUR = 91,20\%), testemunha (PUR $=89,90 \%)$, Sulfometuron metil (PUR $=91,10 \%)$ e C.C. + Glifosato (PUR $=91,20 \%)$ respectivamente (Figura $2 \mathrm{C}$ ), enquanto na safra subsequente este teor ocorreu aos 70 DAA (PUR = $89,10 \%$ ) para o tratamento Glifosato (Figura $2 \mathrm{G}$ ). A interpretação conjunta dos parâmetros PCC, ARC e PUR permitem afirmar que a sacarose exerce influência direta na melhoria da qualidade da matéria-prima. Durante o processo de maturação da cana-de-açúcar há gradativo declínio dos teores de ARC (glicose e frutose), revelando que os mesmos são direcionados para a síntese de sacarose e sua estabilização em níveis mínimos evidencia que pouco restou desses carboidratos para contribuírem com a síntese.

De forma geral, o parâmetro tecnológico $\mathrm{F}$ foi influenciado de forma marcante pelos tratamentos nas safras 2004 e 2005 (Figura 2D, H). Os teores de fibra da cana-de-açúcar foram limitados pela aplicação dos maturadores, enquanto o tratamento-controle foi ajustado ao modelo linear revelando teores crescentes no decorrer das amostragens (Figura 2D, H), embora tenha sido constatado padrão de comportamento semelhante também para os tratamentos Glifosato e C.C. + Glifosato em 2005 (Figura 2H). Os resultados discordam de outros da literatura, os quais têm enfatizado incremento nos valores de fibra na cana em comparação ao controle por meio da aplicação dos maturadores Glifosato e Sulfometuron metil (CASTRO et al., 2002; Fernandes et al., 2002). Por outro lado, CAStro et al. (2003) não observaram diferenças significativas para este parâmetro na cana-de-açúcar variedade RB85 5453 decorrente do uso de Sulfometuron metil.

Tabela 1. Produtividade e margem de contribuição agrícola na colheita da cana-de-açúcar variedade SP803280 sob efeito dos maturadores. Igaraçu do Tietê (SP), $2004 / 2005$

\begin{tabular}{|c|c|c|}
\hline \multirow{2}{*}{ Tratamentos } & \multicolumn{2}{|c|}{ Produtividade de cana } \\
\hline & $2004^{(1)}$ & $2005^{(2)}$ \\
\hline & \multicolumn{2}{|c|}{$\mathrm{t} \mathrm{ha}^{-1}$} \\
\hline Testemunha & 110,60 a & 85,30 a \\
\hline Glifosato & $107,20 \mathrm{a}$ & $79,90 \mathrm{~b}$ \\
\hline Sulfometuron metil & 109,40 a & 83,70 a \\
\hline C.C. + Glifosato & $113,00 \mathrm{a}$ & $85,00 \mathrm{a}$ \\
\hline $\mathrm{CV}(\%)$ & 10,51 & 4,44 \\
\hline \multirow{2}{*}{ Tratamentos } & \multicolumn{2}{|c|}{ Produtividade de açúcar } \\
\hline & $2004^{(1)}$ & $2005^{(2)}$ \\
\hline & \multicolumn{2}{|c|}{$\mathrm{t} \mathrm{ha}^{-1}$} \\
\hline Testemunha & $16,30 \mathrm{~b}$ & $12,50 \mathrm{a}$ \\
\hline Glifosato & $16,70 \mathrm{ab}$ & $11,70 \mathrm{~b}$ \\
\hline Sulfometuron metil & $17,20 \mathrm{a}$ & $13,10 \mathrm{a}$ \\
\hline C.C. + Glifosato & $17,30 \mathrm{a}$ & $12,70 \mathrm{a}$ \\
\hline $\mathrm{CV}(\%)$ & 4,75 & 6,68 \\
\hline \multirow{2}{*}{ Tratamentos } & \multicolumn{2}{|c|}{ Margem de contribuição } \\
\hline & $2004^{(1)}$ & $2005^{(2)}$ \\
\hline & \multicolumn{2}{|c|}{ US\$ ha ${ }^{-1}$} \\
\hline Testemunha & $684,00 \mathrm{~b}$ & $456,50 \mathrm{ab}$ \\
\hline Glifosato & $731,30 \mathrm{ab}$ & $406,00 \mathrm{~b}$ \\
\hline Sulfometuron metil & $757,70 \mathrm{a}$ & 511,10 a \\
\hline C.C. + Glifosato & $756,50 \mathrm{a}$ & $476,00 \mathrm{a}$ \\
\hline$\overline{\mathrm{CV}}(\%)$ & 7,32 & 12,34 \\
\hline
\end{tabular}

Médias seguidas de letras distintas, minúscula na coluna, diferem estatisticamente pelo teste de Duncan a $5 \%$.

( $\left.{ }^{1}\right)$ Safra 2004 = aplicação dos tratamentos em 10/5/2004 e colheita aos 174 dias após aplicação.

$\left({ }^{2}\right)$ Safra 2005 = aplicação dos tratamentos em 4/8/2005 e colheita aos 90 dias após aplicação. 
As condições climáticas favoráveis ao desenvolvimento vegetativo da cultura, principalmente na safra 2004 (Figura 1), podem explicar os teores elevados de fibra da testemunha em relação aos maturadores, tendo em vista que, segundo ESCHRICH (1980) a partição e o acúmulo de sacarose é vital em todas as fases do ciclo de vida vegetal e sua utilização como fonte de energia permite disponibilizar para as células carbono e energia necessários para o processo de respiração e síntese de numerosos compostos diferenciados, dentre estes, os feixes fibrovasculares. Assim, pela interpretação dos parâmetros PCC e F na safra 2004, é possível afirmar que a utilização da sacarose para suprir a demanda metabólica decorrente do desenvolvimento vegetativo comprometeu o acúmulo deste carboidrato nos colmos das plantas não tratadas (Figura 2A, D).

Segundo BARBosa et al. (2007), existe uma associação negativa entre teor de fibras e açúcar, principalmente em variedades precoces, as quais são, em geral, mais ricas em sacarose e com teor de fibra menor.

A quantidade ideal de fibra é variável entre $12 \%$ e $13 \%$, e não compromete a quantidade disponível de bagaço para queima no início da safra.

$\mathrm{Na}$ colheita do experimento foram quantificados os parâmetros TCH e TAH. Os tratamentos influenciaram de forma significativa a TCH somente na safra 2005 (Tabela 1); na qual o tratamento com Glifosato proporcionou menor produção de cana por hectare. Com relação à TAH constatou-se influência significativa dos tratamentos nas safras 2004 e 2005 (Tabela 1). Em 2004, os tratamentos C.C. + Glifosato e Sulfometuron metil proporcionaram a maior produtividade de açúcar, com a testemunha apresentando menor tonelada de açúcar por hectare (Tabela 1). Em 2005, o menor valor de TAH foi determinado pelo tratamento com Glifosato (Tabela 1).

Posteriormente à quantificação do parâmetro $\mathrm{TCH}$ e TAH, foi determinada a margem de contribuição agrícola, sendo constatado influência significativa dos tratamentos nas safras 2004 e 2005 (Tabela 1).

O maior retorno econômico por hectare foi obtido pelos tratamentos Sulfometuron metil e C.C. + Glifosato (Tabela 1). Este resultado evidencia a importância na melhoria da qualidade da matériaprima fornecida à indústria sucroalcooleira, tendo em vista que o incremento em $\mathrm{TAH}$ pode ocasionar reflexo positivo em MCA (Tabela 1). Segundo FERNANDES (2003), o retorno econômico por hectare com o uso de maturadores depende, entre outros fatores, da produtividade agrícola, e em áreas de elevada produtividade, pequenos incrementos na qualidade resultam em favorável vantagem econômica.

Tabela 2. Parâmetros tecnológicos na colheita da cana-de-açúcar, variedade SP80 3280, em função da aplicação de maturadores em meio de safra. Igaraçu do Tietê (SP), 2004/2005

\begin{tabular}{|c|c|c|c|c|}
\hline \multirow{2}{*}{ Tratamento } & \multicolumn{4}{|c|}{ Safra $2004(174 \text { DAA })^{(1)}$} \\
\hline & PCC & ARC & PUR & F \\
\hline Testemunha & $14,74 \mathrm{~b}$ & $0,51 \mathrm{a}$ & $88,68 \mathrm{c}$ & $12,03 \mathrm{a}$ \\
\hline Glifosato & $15,62 \mathrm{a}$ & $0,48 \mathrm{~b}$ & $89,60 \mathrm{~b}$ & $11,79 \mathrm{ab}$ \\
\hline Sulfometuron metil & 15,68 a & $0,47 \mathrm{bc}$ & $89,70 \mathrm{ab}$ & $11,65 \mathrm{~b}$ \\
\hline C.C. + Glifosato & $15,35 \mathrm{a}$ & $0,45 \mathrm{c}$ & 90,48 a & $11,56 \mathrm{~b}$ \\
\hline CV (\%) & 2,51 & 4,69 & 1,78 & 3,30 \\
\hline \multirow{2}{*}{ Tratamento } & \multicolumn{4}{|c|}{ Safra 2005 (90 DAA) $^{(2)}$} \\
\hline & PCC & ARC & PUR & $\mathrm{F}$ \\
\hline Testemunha & $14,65 \mathrm{~b}$ & $0,47 \mathrm{~b}$ & $89,15 \mathrm{ab}$ & $13,99 \mathrm{a}$ \\
\hline Glifosato & $14,63 \mathrm{~b}$ & $0,49 \mathrm{a}$ & $88,66 \mathrm{~b}$ & $13,51 \mathrm{~b}$ \\
\hline Sulfometuron metil & 15,67 a & $0,46 \mathrm{~b}$ & $89,68 \mathrm{a}$ & $13,42 \mathrm{~b}$ \\
\hline C.C. + Glifosato & $14,99 \mathrm{~b}$ & 0,49 a & $88,80 \mathrm{~b}$ & $13,31 \mathrm{~b}$ \\
\hline CV (\%) & 2,78 & 3,40 & 0,94 & 2,91 \\
\hline
\end{tabular}

Médias seguidas de letras distintas, minúscula na coluna, diferem estatisticamente pelo teste de Duncan a $5 \%$.

(1) Safra 2004 = aplicação dos tratamentos em 10/5/2004 e colheita aos 174 dias após aplicação.

$\left({ }^{2}\right)$ Safra 2005 = aplicação dos tratamentos em 4/8/2005 e colheita aos 90 dias após aplicação. 
Na safra 2004, a inclusão da prática de aplicação de maturadores no sistema de produção da cana-de-açúcar ofereceu condições para que a variedade manifestasse seu potencial de acúmulo de sacarose, sendo constatado por ocasião da colheita teores de PCC superiores à testemunha, contribuindo para o aumento da PUR e redução nos teores de ARC e F (Tabela 2). Na safra 2005, o maturador Sulfometuron metil elevou a PCC e a PUR em relação aos demais tratamentos, associado ao menor valor de ARC (Tabela 2). Esses resultados indicam a dependência dos efeitos dos maturadores em relação às condições ambientais.

Na literatura, é comum a recomendação da aplicação de Glifosato em variedades precoces de cana-de-açúcar, cuja época de maior eficiência compreende o período entre fim de março e meados de abril (ROMERO et al., 1998), em função de resultados consistentes quanto a incrementos na PCC (ROMERO et al., 1996; Romero et al., 2000). No entanto, os resultados obtidos quanto à determinação dos parâmetros tecnológicos na colheita (Tabela 2) permitem inferir sobre a eficiência agronômica deste agente químico quando utilizado em maio, o que segundo Romero et al. (1996), está associado às condições ambientais favoráveis à sua ação e, assim, sendo capaz de restringir de forma marcante o desenvolvimento vegetativo do canavial.

\section{CONCLUSÕES}

1. A eficiência agronômica dos maturadores foi influenciada pela condição climática de cada safra.

2. A aplicação dos maturadores em meia estação (maio) permitiu explorar de forma significativa o potencial genético da variedade quanto ao acúmulo de sacarose nos colmos, resultando em melhoria na qualidade tecnológica da matéria-prima, porém sem efeito significativo na produtividade de colmos por hectare.

3. Os maturadores influenciaram de forma significativa a produtividade de açúcar, aumentando o retorno econômico por hectare.

\section{AGRADECIMENTOS}

À Fundação de Amparo à Pesquisa do Estado de São Paulo (Fapesp), pela concessão de bolsa de estudo a Glauber Henrique Pereira Leite. Ao CNPq pela bolsa de produtividade em pesquisa a Carlos Alexandre Costa Crusciol. Ao Grupo COSAN - Unidade Barra (Usina da Barra), pela permissão de realização do experimento em sua área experimental.

\section{REFERÊNCIAS}

ALMEIDA, J.C.V.; SANOMYA, R.; LEITE, C.F.; CASSINELLI, N.F. Eficiência agronômica de sulfometuron methil como maturador na cultura da cana-de-açúcar. STAB, Piracicaba, v.21, n.3, p.36-37, 2003.

BARBOSA, M.H.P.; SILVEIRA, L.C.I.; MACÊDO, G.A.R.; PAES, J.M.V. Variedades melhoradas de cana-de-açúcar para Minas Gerais. Informe Agropecuário, Belo Horizonte, v.28, n.239, p.20-24, 2007.

CAPUTO,M.M.;BEAUCLAIR.E.G.F.;SILVA,M.A.;PIEDADE,S.M.S. Resposta de genótipos de cana-de-açúcar à aplicação de indutores de maturação. Bragantia, Campinas, v.67, n.1, p.15-23, 2008.

CASTRO, P.R.C. Maturadores químicos em cana-de-açúcar. Saccharum, v.1, p.12-16, 1999.

CASTRO, P.R.C. Aplicações da fisiologia vegetal no sistema de produção da cana-de-açúcar. In: SIMPÓSIO INTERNACIONAL DE FISIOLOGIA DA CANA-DE-AÇÚCAR, 2000, Piracicaba. Anais... Piracicaba: STAB, 2000a. 9p.

CASTRO, P.R.C. Utilização de reguladores vegetais no sistema de produção da cana-de-açúcar. In: SIMPÓSIO INTERNACIONAL DE FISIOLOGIA DA CANA-DEAÇÚCAR, 2000, Piracicaba. Anais... Piracicaba: STAB, 2000b. 10p.

CASTRO, P.R.C.; CÂMARA, G.M.S.; CÉSAR, M.A.A.; NOGUEIRA, M.C.S. Ação comparada de maturadores em dois cultivares de cana-de-açúcar. Álcool e Açúcar, v.73, p.36-39, 1994.

CASTRO, P.R.C.; DONADONI, P.C.I.; PAGGIARO, C.M.; WATANABE, S.; TAVARES, S.; PANINI, E.L. Afinidade do sulfometuron metil com adjuvantes. STAB, Piracicaba, v.22, n.2, p.42-43, 2003.

CASTRO, P.R.C.; OLIVEIRA, D.A.; PANINI, E.L. Ação do sulfometuron metil como matuirador da cana-de-açúcar. In: CONGRESSO NACIONAL DA STAB, 6., 1996, Maceió. Anais... Maceió: STAB, 1996. p.363-369.

CASTRO, P.R.C.;ZAMBON, S.;SANSÍDOLO, M.A.; BELTRAME, J.A.; NOGUEIRA, M.C.S. Ação comparada de Ethrel, Fuzilade e Glifosato, em duas épocas de aplicação, na maturação e produtividade da cana-de-açúcar, variedade SP 70-1143. Revista de Agricultura, Piracicaba, v.77, n.1, p.23-38, 2002.

COOPERATIVA DE PRODUTORES DE CANA, AÇÚCAR E ÁlCOOL DO ESTADO DE SÃO PAULO LTDA. Sexta geração de variedades de cana-de-açúcar Copersucar. Piracicaba, 1997. Edição Especial. (Boletim Técnico COPERSUCAR)

DEUBER, R. Maturação da cana-de-açúcar na região Sudeste do Brasil. In: SEMINÁRIO DE TECNOLOGIA AGRONÔMICA, 4., 1988, Piracicaba. Anais... Piracicaba: Copersucar, 1988. p.33-40.

ESCHRICH, W. Free space invertase, its possible role in phloem unloading. Bericht Deutschen Botanischen Geselschaft, n.93, p. 363-378, 1980. 
FERNANDES, A.C. Cálculos na agroindústria da cana-deaçúcar. Piracicaba: STAB, 2003. 240 p.

FERNANDES, A.C.; STUPIELLO, J.P.; UCHOA, P.E.A. Utilização do Curavial para melhoria da qualidade da canade-açúcar. STAB, Piracicaba, v.20, n.4, p.43-46, 2002.

MUTTON, M.J.R.; MUTTON, M.A. Aguardente de cana: produção e qualidade. Jaboticabal: Funep, 1992. 171p.

ROMERO, E.R.; SCANDALIARIS, J.; OLEA, I.; DIAZ, H.; SOTILLO, S.; DURÁN, A. La maduración en caña de azúcar. II. El glifosato como madurador químico. Avance Agroindustrial, Tucumán, v.17, n.66, p.14-18, 1996.

ROMERO, E.R.; SCANDALIARIS, J.; RUFINO, M.; DURÁN, A.; DIAZ, F. Respuesta de la caña de azúcar a la aplicación de glifosato como madurador. I. Efectos en la calidad fabril e influencia de los factores ambientales. Avance Agroindustrial, Tucumán, v.19, n.74, p.7-10, 1998.

ROMERO, E.R.; SCANDALIARIS, J.; RUFINO, M.; DURÁN, A.; SOTOMAYOR, L.; QUIROGA, V.; MORALES, M. Actualización de las recomendaciones de manejo de glifosato como madurador de la caña de azúcar. Avance Agroindustrial, v.21, n.22, p.22-27, 2000.

ROMERO,E.R.; SOTOMAYOR, L.; TONATTO, J.; ALONSO, L.; SCANDALIARIS, J.; NEME, M.F.L. Maduración química de los cañaverales: criteios y recomendaciones para implementar un programa de manejo. Avance Agroindustrial, Tucumán, v.24, n.1, p.10-14, 2003. 